\title{
LEITE EM PÓ DESNATADO NÃO INATIVADO E LEITE DESNATADO UHT PARA PRESERVAÇÃO E FERTILIDADE DO SÊMEN EQÜINO RESFRIADO
}

\author{
THE USE OF NOT INACTIVATED NONFAT DRY MILK AND UHT SKIM MILK IN THE \\ PRESERVATION AND FERTILITY OF COOLED EQUINE SEMEN
}

\author{
Luciana Silva Meirelles ${ }^{1}$ Eduardo Malschitsky ${ }^{1}$ Adriana Pires Neves ${ }^{1}$ Magda Jochims Vieira' \\ Andrea Keller ${ }^{1}$ Arthur Kardel Hött ${ }^{2}$ Iara Marília Antoniazzi de Moraes ${ }^{2}$ Petra Garbade $^{3}$ \\ Ricardo Macedo Gregory ${ }^{3}$ Rodrigo Costa Mattos $^{34}$
}

\section{RESUMO}

$O$ presente estudo foi delineado com o objetivo de verificar a necessidade de inativar o leite em pó desnatado reconstituido, bem como o uso do leite desnatado UHT como diluente de sêmen eqüino resfriado. Para tanto, foram efetuados dois experimentos. No primeiro experimento, 4 diluentes foram testados: leite desnatado não inativado, leite desnatado inativado, leite desnatado UHT, marca A e leite desnatado UHT marca B. 20 coletas de sêmen foram realizadas. $O$ sêmen resfriado $a+4^{\circ} \mathrm{C}$ foi avaliado quanto à motilidade progressiva e motilidade total nas 0,24 e 48 horas posteriores à diluição. No segundo experimento, um total de 101 ciclos foram utilizados, inseminando-se as éguas com sêmen diluído em leite desnatado não inativado e leite desnatado inativado. A diluição foi realizada numa proporção de $1: 2$ (sêmen:diluente) $e$ a dose inseminante minima utilizada foi de $500 \times 10^{6}$ espermatozóides. Conclui-se que não há necessidade de inativar o leite em pó desnatado, reconstituido, na sua utilização como diluente de sêmen eqüino resfriado, e que o leite desnatado UHT pode ser utilizado como diluente para preservar sêmen eqüino resfriado.

Palavras chave: eqüinos, sêmen resfriado, leite

\section{SUMMARY}

The present study was designed aiming to verify the need of inactivating reconstituted nonfat dry milk and the use of skim milk UHT as extender for cooling equine semen. Two experiments were performed. In the first experiment, four diluents were tested: reconstituted not-inactivated dry skim milk, inactivated reconstituted dry skim milk, UHT skim milk A and UHT skim milk $B$. Twenty semen collections were obtained. Semen were cooled at $+4^{\circ} \mathrm{C}$ and evaluated for progressive and total motility 0,24 and 48 $h$ after collection. In the second experiment, one hundred and one cycles were studied. Mares were inseminated with semen diluted in inactivated and not-inactivated dry skim milk. Dilution was done in a 1:2 (semen:diluent) ratio and the minimal inseminating dosis used was $500 \times 10^{6}$ spermatozoa. It was concluded that it is not necessary to inactivate nonfat dry milk for using it to dilute equine semen and that skim milk UHT may be used to dilute and preserve chilled equine semen.

Key words: equine, cooled semen, milk

\section{INTRODUÇÃO}

Em eqüinos, a inseminação artificial com sêmen fresco resulta em fertilidade similar à da monta natural (MATTOS \& CAVALHEIRO, 1988; MATTOS et al., 1996), porém oferece vantagens, como maior taxa de prenhez por ciclo, maior número de éguas servidas por garanhão e redução da transmissão venérea (BRINSKO \& VARNER, 1992).

Os diluentes de sêmen destinam-se a prolongar a vida fértil do espermatozóide e a protegê-lo de condições ambientais desfavoráveis (PICKETT \& AMANN, 1987; BRINSKO \& VARNER, 1992). Um dos diluentes mais usados para preservação de sêmen eqüino é o leite desnatado (VOSS \& PICKETT, 1976), este pode ser beneficiado como leite UHT (ultra-heattreatment) ou como leite em pó. O leite UHT possui uma conservação indefinida, pois no processo há destruição completa de germes e esporos que podem

\footnotetext{
'Médico Veterinário, Aluno de Mestrado do CPG em Ciências Veterinárias.

${ }^{2}$ Bolsista de Iniciação Científica CNPq-PIBIC-UFRGS

${ }^{3}$ Professor Adjunto.

${ }^{4}$ Laboratório de Reprodução Animal/REPROLAB; Departamento de Medicina Animal, FacuIdade de Veterinária - UFRGS, Av. Bento Gonçalves 9090, 91540-000, Porto Alegre, Brasil. Autor para correspondência.
} 
mudar a composição organoléptica do leite. Na elaboração do leite em pó ocorre o processo de pulverização em ar quente, aumentando o tempo de sua conservação (VEISSEYR, 1972). Na fração protéica do leite há fatores tóxicos ao espermatozóide (HOUSEHOLDER et al., 1981; EVANS \& MAXWELL, 1987), sendo um deles a lactenina, proteína de baixo peso molecular e bactericida para cepas de Streptococcus spp no leite fresco, a qual seria inativada $\mathrm{a}+92^{\circ} \mathrm{C}$ por 10 minutos (FLIPSE $\boldsymbol{e t}$ al., 1954). O leite UHT não necessita ser inativado previamente quando utilizado como diluente de sêmen, ao contrário do leite em pó reconstituído (EVANS \& MAXWELL, 1987). Existem inúmeros trabalhos que utilizam o leite desnatado como diluente. Entretanto, não há relatos sobre a inativação ou não do leite desnatado em pó na conservação do sêmen eqüino.

O presente trabalho tem como objetivos: comparar leite em pó desnatado reconstituído inativado, leite em pó desnatado reconstituído sem inativar e leite desnatado UHT de dois fornecedores, quanto à capacidade de preservação da motilidade do sêmen eqüino resfriado; comparar a fertilidade do sêmen diluído em leite em pó desnatado reconstituído inativado e em leite em pó desnatado reconstituído não inativado, em relação à fertilidade obtida com o sêmen fresco.

\section{MATERIAIS E MÉTODOS}

Experimento 1: Efeito de diferentes diluentes à base de leite sobre a motilidade espermática do sêmen eqüino resfriado.

Foram utilizados dois garanhões em atividade sexual e com idades variando entre 6 e 14 anos. Os animais estavam alojados na Faculdade de Veterinária da UFRGS. A alimentação era composta por pastagens naturais e suplementada com concentrado.

Neste experimento, 4 diluentes foram testados: leite desnatado não inativado (dissolveram-se $5 \mathrm{~g}$ de leite em pó desnatado com $0,1 \%$ de gordura em água bidestilada até um volume final de $50 \mathrm{ml}$ ), leite desnatado inativado (dissolveram-se $5 \mathrm{~g}$ de leite em pó ${ }^{1}$ desnatado com $0,1 \%$ de gordura em água bidestilada até um volume de $50 \mathrm{ml}$, esta solução foi incubada a $+95^{\circ} \mathrm{C}$ durante 10 minutos), leite desnatado UHT marca $\mathrm{A}^{2}$ (leite desnatado com $0,5 \%$ de gordura beneficiado pela Parmalat pelo sistema UHT) e leite desnatado UHT marca $\mathrm{B}^{3}$ (leite desnatado com $0,1 \%$ de gordura beneficiado pela Elegê pelo sistema UHT).

Um total de 20 coletas foi utilizado. Após cada coleta o sêmen foi imediatamente avaliado quanto à motilidade e concentração. Os diluentes foram acondicionados em tubos de $10 \mathrm{ml} \mathrm{e}$ incubados a $+35^{\circ} \mathrm{C}$ até o momento da utilização. Em cada ejacula- do, uma quantidade determinada de sêmen foi adicionada a cada um dos diluentes, de maneira a se alcançar uma taxa de diluição superior a 1:2 e uma concentração final, variando entre 25 a $50 \times 10^{6}$ espermatozóides por ml. $\mathrm{O}$ sêmen foi avaliado quanto à motilidade progressiva e motilidade total nas 0,24 e 48 horas posteriores à diluição. $\mathrm{O}$ resfriamento das amostras foi realizado imediatamente após a primeira avaliação da motilidade $(0 \mathrm{~h})$, mediante a colocação das amostras em refrigerador a $+4^{\circ} \mathrm{C}$, obtendo-se uma velocidade inicial de resfriamento igual a $1^{\circ} \mathrm{C} / \mathrm{min}$. Uma alíquota de sêmen fresco sem diluir serviu de controle. A cada coleta foi utilizada uma partida diferente de leite.

Foi utilizada a análise de variância considerando o experimento em parcelas subdivididas. $\mathrm{O}$ procedimento foi realizado no programa SAS e, para a comparação de médias, foi usado o teste de LSMEANS. As diferenças foram consideradas significativas no nível de probabilidade de 0,05 .

Experimento 2: Teste a campo da fertilidade do sêmen diluído

Foram utilizadas 96 éguas reprodutivamente sadias e 5 garanhões em atividade sexual e aptos à reprodução, alojados numa mesma propriedade. O regime alimentar era composto por pastagem nativa e complementado com concentrado. Um total de 101 ciclos foi utilizado. O ciclo estral das éguas e o desenvolvimento folicular foram controlados através de palpação retal e ultra-sonografia. Após as coletas, o sêmen foi avaliado com relação à motilidade e à concentração e imediatamente diluído. Os diluentes utilizados foram leite desnatado não-inativado e leite desnatado inativado. A diluição foi realizada numa proporção de 1:2 (sêmen:diluente) e a dose inseminante mínima utilizada foi de $500 \times 10^{6}$ espermatozóides.

As éguas foram designadas aleatoriamente a um dos dois tratamentos: inseminação com sêmen diluído em leite em pó desnatado não inativado ou com sêmen diluído em leite em pó desnatado inativado. A inseminação foi efetuada até no máximo 1 hora após a coleta. A primeira inseminação foi realizada quando detectou-se um folículo maior que $35 \mathrm{~mm}$ e com consistência frouxo-elástica. Quando necessário, as inseminações foram repetidas com o mesmo diluente, a cada 48 horas, até a detecção da ovulação. $\mathrm{O}$ diagnóstico de gestação foi realizado aos 13 dias por ultra-sonografia.

Os resultados de prenhez obtidos com os dois diluentes testados (leite inativado e não inativado) foram comparados pelo teste de Qui-quadrado. As diferenças foram consideradas significativas no nível de probabilidade de 0,05. 


\section{RESULTADOS}

\section{Experimento 1}

A motilidade progressiva e a motilidade total do sêmen equiino diluído com os quatro diluentes à base de leite, durante os tempos $0 \mathrm{~h}, 24 \mathrm{~h}$ e $48 \mathrm{~h}$ encontram-se representados na Tabela 1 e na Tabela 2. Não se observaram diferenças significativas na motilidade progressiva e na motilidade total na hora 0 no sêmen diluído com os quatro diluentes. Entretanto, nas 24 h, observou-se que o sêmen diluído com o leite beneficiado pelo sistema UHT, da marca A, apresentou perda mais acentuada e significativa de motilidade total e de motilidade progressiva, quando comparado com os demais diluentes. Essa diferença desapareceu nas 48 horas, quando as motilidades do sêmen diluído com os quatro diluentes se equivaleram significativamente. $\mathrm{O}$ grupo controle não foi relacionado, tendo em vista que nas primeiras 24 horas todos os espermatozóides encontravam-se imóveis. Foi observada uma variabilidade muito grande entre as partidas de leite

\begin{tabular}{lccc}
$\begin{array}{l}\text { Tabela } 1 \text { - Motilidade progressiva }(\%) \\
\text { rentes tempos e diluentes. }\end{array}$ \\
\hline Tratamentos & \multicolumn{3}{c}{ Tempos observada nos dife- } \\
& & $24 \mathrm{~h}$ & $48 \mathrm{~h}$ \\
\hline & $48^{\mathrm{a}}$ & $18^{\mathrm{b}}$ & $5^{\mathrm{e}}$ \\
\hline $\begin{array}{l}\text { Leite desnatado não-inativado } \\
\text { Leite desnatado inativado }\end{array}$ & $48^{\mathrm{a}}$ & $21^{\mathrm{b}}$ & $6^{\mathrm{e}}$ \\
$\begin{array}{l}\text { Leite desnatado esterilizado marca A } \\
\text { Leite desnatado esterilizado marca B }\end{array}$ & $49^{\mathrm{a}}$ & $14^{\mathrm{c}}$ & $5^{\mathrm{e}}$ \\
Controle & $17^{\mathrm{b}}$ & $6^{\mathrm{e}}$ \\
& $44^{\mathrm{a}}$ & $0^{\mathrm{d}}$ & $0^{\mathrm{f}}$ \\
\hline
\end{tabular}

$(\mathrm{a}, \mathrm{b}, \mathrm{c}, \mathrm{d}, \mathrm{e}, \mathrm{f})$ letras diferentes nas colunas representam diferenças significativas $(\mathrm{P}<0,05)$.

Tabela 2 - Motilidade total $(\%)$ média observada nos diferentes tempos e diluentes.

\begin{tabular}{lccc}
\hline Tratamentos & \multicolumn{3}{c}{ Tempos } \\
& $0 \mathrm{~h}$ & $24 \mathrm{~h}$ & $48 \mathrm{~h}$ \\
\hline & $68^{\mathrm{a}}$ & $39^{\mathrm{b}}$ & $14^{\mathrm{e}}$ \\
Leite desnatado não-inativado & $67^{\mathrm{a}}$ & $40^{\mathrm{b}}$ & $16^{\mathrm{e}}$ \\
Leite desnatado inativado & $69^{\mathrm{a}}$ & $33^{\mathrm{c}}$ & $11^{\mathrm{e}}$ \\
Leite desnatado esterilizado marca A & $67^{\mathrm{a}}$ & $34^{\mathrm{bc}}$ & $15^{\mathrm{e}}$ \\
Leite desnatado esterilizado marca B & $67^{\mathrm{a}}$ & $6^{\mathrm{d}}$ & $0^{\mathrm{f}}$ \\
Controle & 6 & & \\
\hline
\end{tabular}

(a,b,c,e,d,f) letras diferentes nas colunas representam diferenças significativas $(\mathrm{P}<0,05)$
UHT, de ambas as marcas, em relação à motilidade progressiva e à motilidade total, ao contrário do observado no leite em pó reconstituído.

\section{Experimento 2}

$\mathrm{Na}$ tabela 3 estão demonstrados os índices de fertilidade obtidos em ambos os tratamentos. Não foi detectada diferença significativa nos índices de prenhez de éguas inseminadas com sêmen eqüino, diluído em leite em pó desnatado reconstituído inativado e com sêmen diluído em leite em pó desnatado reconstituído e não inativado.

\section{DISCUSSÃO}

A adição de diluentes ao sêmen prolongou significativamente a manutenção da motilidade. De fato, os diluentes são considerados o fator mais importante na preservação dos espermatozóides (MANN \& LUTWAK-MANN, 1981), e existe consenso quanto à capacidade dos diluentes protegerem e prolongarem a vida das células espermáticas (PICKETT \& AMANN, 1987).

Os diluentes utilizados neste trabalho mostraram ser adequados para preservação dos espermatozóides a $+4^{\circ} \mathrm{C}$, obtendo-se resultados semelhantes aos de MATTOS (1994) em relação à manutenção das motilidades progressiva e total e aos de MATTOS \& CAVALHEIRO (1988); MATTOS (1994) e MATTOS et al. (1996) em relação à fertilidade.

Não se observaram diferenças significativas em relação à motilidade progressiva, motilidade total e fertilidade entre o leite desnatado inativado e o leite desnatado não inativado, demonstrando que o processo de inativação não é necessário, quando se utiliza leite em pó, não concordando com os achados de EVANS \& MAXWELL (1987). A lactenina, fator tóxico ao espermatozóide, é inativada pelo calor, aparentemente pela liberação de grupos sulfídricos das lactoglobulinas que posteriormente se juntam à lactenina, eliminando seu fator tóxico (JOHNSON et al., 1955). Pro-

Tabela 3 - Taxa de prenhez por ciclo nos diferentes tratamentos.

\begin{tabular}{|c|c|c|c|}
\hline Diluentes & $\begin{array}{c}\text { Ciclos } \\
\mathrm{n}\end{array}$ & $\begin{array}{c}\text { Prenhez } \\
n\end{array}$ & $\%$ \\
\hline $\begin{array}{l}\text { leite desnatado não-inativado } \\
\text { leite desnatado inativado }\end{array}$ & $\begin{array}{l}47 \\
54\end{array}$ & $\begin{array}{l}32 \\
39\end{array}$ & $\begin{array}{l}68,0^{\mathrm{a}} \\
72,2^{\mathrm{a}}\end{array}$ \\
\hline
\end{tabular}


vavelmente, no processo de beneficiamento do leite em pó, ocorra a inativação da lactenina. A não necessidade de inativar o leite em pó elimina um processo demorado, que pode constituir uma fonte de erro (PICKETT \& AMANN, 1987), possibilitando o rápido preparo do diluente com produtos comercialmente disponíveis (MATTOS, 1994). O leite em pó desnatado reconstituído, desde que preparado com ingredientes de boa qualidade, apresenta resultados de preservação da motilidade e da fertilidade satisfatórios e constantes.

A utilização de leite desnatado e beneficiado pelo sistema UHT permitiu uma boa manutenção da motilidade do sêmen eqüino resfriado. Entretanto, observou-se uma grande variabilidade entre as diferentes partidas de leite, não permitindo que ocorressem resultados constantes. $\mathrm{O}$ leite da marca A permitiu queda significativa de motilidade às 24 horas, quando comparado com os demais diluentes. Este fato pode estar relacionado à maior quantidade de gordura apresentada por este diluente, provocando uma maior aglutinação dos espermatozóides.

O presente trabalho permite concluir que não há necessidade de inativar o leite em pó desnatado, reconstituído, na sua utilização como diluente de sêmen eqüino resfriado, e que o leite desnatado UHT pode ser utilizado como diluente para preservar sêmen eqüino resfriado.

\section{FONTES DE AQUISIÇÃO}

\footnotetext{
'Molico, Nestlé, Araras, SP

${ }^{2}$ Parmalat, Lacesa SA, Feliz, RS

${ }^{3}$ Elegê, CCGL SA, Teutônia, RS
}

\section{REFERÊNCIAS BIBLIOGRÁFICAS}

BRINSKO, S.P., VARNER, D.D. Artificial insemination and preservation of semen. In: BLANCHARD, T.L., VARNER, D.D. Stallion management. Vet Clin North America: Equine Practice, v. 8, n. 1, p. 205-218, 1992
EVANS, G., MAXWELL, W.M.C. Salamon's artificial insemination of sheep and goats. Sydney: Butterworth, 1987. 194 p.

FLIPSE, R.J., PATTON, S., ALQUIMST, J.O. Diluters for bovine semen. III. Effect of lactenin and of lactoperoxidase upon spermatozoa viability. J Dairy Sci, Urbana-Illinois, v. 37, p. 1205-1211, 1954

HOUSEHOLDER, D.D., PICKETT, B.W., VOSS, J.L., et al. Effect of extender, number of spermatozoa and HCG on equine fertility. J Equine Vet Sci Wildomar-California, n. 1, p. 9-13, 1981.

JOHNSON. P.E., FLIPSE, R.J., ALMQUIST, J.O. Diluters for bovine semen. VI. The effect of cysteine hydrochloride on the liveability of bull spermatozoa in unheated skim milk. J Dairy Sci v. 38, p. 53-57, 1955.

MANN, T., LUTWAK-MANN, C. Male reproductive function and semen. Berlin: Springer Verlag, 1981.

MATTOS, R. Influência de diferentes métodos de preservação de sêmen equiino sobre a fertilidade, motilidade espermática e contaminação bacteriana. Tese (Mestrado em Ciências Veterinárias) - Faculdade de Veterinária, Universidade Federal do Rio Grande do Sul, Porto Alegre, 1994.

MATTOS, R.C., CAVALHEIRO, E.P. Monta natural e inseminação artificial com sêmen fresco em éguas cruza Árabe. In: CONGRESSO ESTADUAL DE MEDICINA VETERINÁRIA, 10., 1988, Porto Alegre, Anais... Porto Alegre: Sociedade de Veterinária do Rio Grande do Sul, 1988, p. 46.

MATTOS, R.C., CAVALHEIRO ,E.P., MATTOS, R., et al. Monta natural e inseminação artificial com sêmen fresco diluído em éguas Árabe. Arq Fac Vet UFRGS, Porto Alegre, v. 24, n. 2, p. 57-64, 1996.

PICKETT, B.W., AMANN, R.P. Extension and storage of stallion spermatozoa: a review. J Eq Vet Sci, Wildomar - California, v. 7 , n. 5 , p. 289-302,1987.

VEISSEYRE, R. Lactologia Tecnica. 2. ed. Zaragoza: Acribia, 1972, $644 \mathrm{p}$.

VOSS , J.L., PICKETT, B.W. Reproductive management of the broodmare. Colorado State University Exp. Stat. Anim. Reprod. Lab., 1976, p. 22 (Gen. Series Bulletin 961).

Ciência Rural, v. 28, n. 3, 1998. 